\title{
Erratum to: Promoting Female Condom Use Among Female University Students in KwaZulu-Natal, South Africa: Results of a Randomized Behavioral Trial
}

\author{
Joanne E. Mantell ${ }^{1}$ Jennifer A. Smit ${ }^{2,3}$ - Theresa M. Exner ${ }^{1} \cdot$ Zonke Mabude $^{2}$. \\ Susie Hoffman ${ }^{1,4}$ - Mags Beksinska ${ }^{2}$ - Elizabeth A. Kelvin ${ }^{1,5}$ - Claudia Ngoloyi ${ }^{2}$. \\ Cheng-Shiun Leu ${ }^{1,6} \cdot$ Zena A. Stein ${ }^{1,7}$
}

Published online: 21 July 2015

(C) Springer Science+Business Media New York 2015

\section{Erratum to: AIDS Behav \\ DOI 10.1007/s10461-014-0860-6}

In the original version of the article, Fig. 1 was published incorrectly. The corrected Fig. 1 is given here.

The online version of the original article can be found under doi:10.1007/s10461-014-0860-6.

Joanne E. Mantell

jem57@cumc.columbia.edu; jmantell@verizon.net

1 HIV Center for Clinical and Behavioral Studies, New York State Psychiatric Institute and Columbia University, 1051 Riverside Drive, Unit 15, New York, NY 10032, USA

2 Department of Obstetrics and Gynaecology, Faculty of Health Sciences, Maternal, Adolescent and Child Health Research (MatCH Research), University of the Witwatersrand, Durban 3629, South Africa

3 School of Pharmacy and Pharmacology, Faculty of Health Sciences, University of KwaZulu-Natal, Durban 3627, South Africa

4 Department of Epidemiology, Mailman School of Public Health at Columbia University, New York, NY 10032, USA
5 City University of New York School of Public Health, Hunter College, Epidemiology and Biostatistics Program, New York, NY 10035, USA

6 Department of Biostatistics, Mailman School of Public Health at Columbia University, New York, NY 10032, USA

7 GH Sergievsky Center, Joseph Mailman School of Public Health Columbia University, New York, NY 10032, USA 


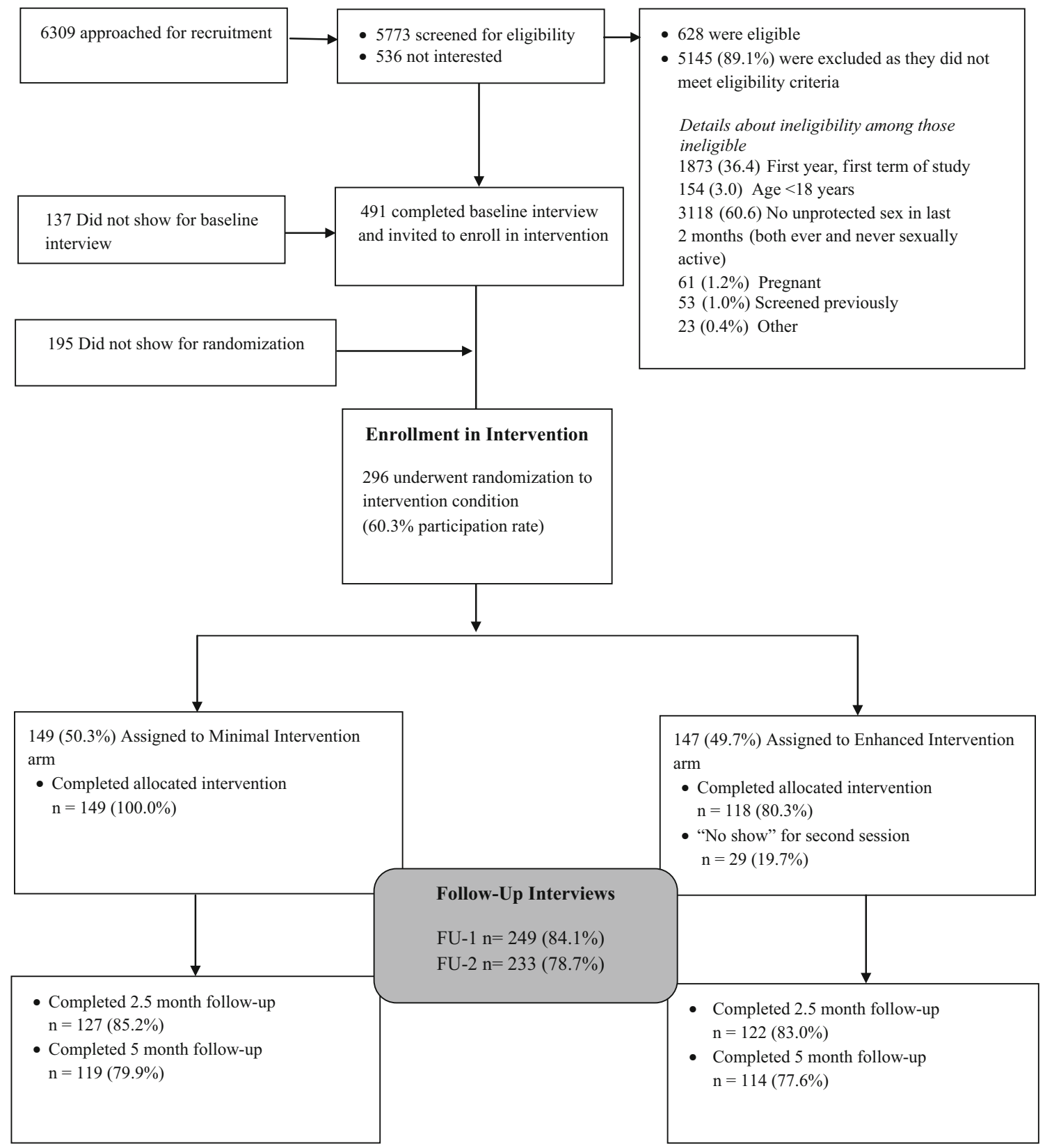

Fig. 1 Overview of study enrollment and flow 